\title{
Regulation of Digital Platforms in Russia: A Glimpse into the Future
}

\author{
Yushchenko N.A. ${ }^{1 *}$ Gumerova E.F. ${ }^{2}$ \\ ${ }^{1}$ Kazan Federal University, Naberezhnye Chelny Institute, Naberezhnye Chelny, Russia \\ ${ }^{2}$ Kazan Innovative University named after V.G.Timiryasov (KIU), Naberezhnye Chelny Branch, Naberezhnye Chelny, \\ Russia \\ *Corresponding author. Email: NAJuschenko@kpfu.ru
}

\begin{abstract}
A significant increase in regulatory activities throughout the world requires the development of a harmonized legal framework with the aim of protecting consumer rights, increasing the transparency of entrepreneurs, maintaining healthy competition, and protecting confidential information. The paper presents the author's view on the model of legal regulation of digital platforms in Russia. The five structural elements of the system of Russian legislation that are to be fixed in the rules of law are indicated. The authors have developed three theories of the features of the functioning of digital platforms, i.e. the theory of control and data management, the theory of the gratuitousness of the services of digital platforms, and the theory of competition of digital platforms, which should be put into the antitrust doctrine. It is confirmed that some countries have begun lawmaking activities to improve legislation but only in some areas. The conclusion is drawn on the formation of a single concept of legal regulation of digital platforms in Russia.
\end{abstract}

Keywords: digital market, digital platform, digital right, competition, confidential information, antitrust law

\section{INTRODUCTION}

The increased international attention to digital platforms, the business models they use, and the user data they collect demonstrate their significant and widespread influence. Digital platforms play a central role in the economy and in our daily lives. Their rapid development since the advent of the public commercial Internet over 20 years ago brought many social benefits and new opportunities for consumers and entrepreneurs [1].

The point is in digital platforms, such as online search engines, social media platforms, and other digital content aggregation platforms. This applies in large part to Google and Facebook, the size of which affects the entire global economy. Significant opportunities provided by digital platforms may give rise to potentially adverse consequences for society and the economy due to their growth, which should be taken into account when improving legal regulation.

Digital platforms, as market participants, mainly affect three user groups: advertisers, media content creators, and consumers. They also affect the mass media. Two relationships appear here: the first is an increase or decrease in the quality of information, primarily news, the second is an increase or decrease in consumer demand for goods (work, services). The negative role of the influence of digital platforms can be distinguished as the promotion of terrorist, extremist, or other malicious content and/or the use of social media for political advertising.
Increased competition among digital platforms is achieved through the protection of confidential information, which strengthens consumer confidence in online markets. By strengthening the mechanism for protecting confidential information and data, they may give consumers the opportunity to choose how to process their data more consciously. This, in turn, intensifies competition among digital platforms regarding the confidentiality of their services.

The widespread and frequent use of Google and Facebook means that these platforms occupy a key place for companies seeking to attract consumers. Google and Facebook may effectively facilitate entry into one or more markets, depending on the category of online customers.

The ability to determine the content and relevance of materials displayed to consumers, as well as the ability to establish conditions for access to their services, provide Google and Facebook with the opportunity to take advantage of their own business. The significant amount of data that these platforms collect cannot be easily obtained to gain a competitive advantage.

The pursuit of growth and profit on the part of business lies at the heart of the effective functioning of a market economy. Nevertheless, the state and society, in general, should remember that the actions of digital platforms, similar to all entrepreneurs, will be driven by the motive for more profit. This does not mean that digital platforms seek to harm consumers and society but they are able to do it as a part of the task of making a profit. The state should take into account that some decisions on the dissemination 
of information, the collection of personal data, and the interaction of business with consumers on the Internet may be left to the discretion of some large digital platforms, given their significant market share, prevalence, and their inherent motive for profit. However, legislation should provide for restraining measures aimed at influencing digital platforms in the domestic and global markets.

\section{RESEARCH METHODOLOGY}

The structural elements of the legal regulation of the activities of digital platforms should be systemic in nature and reflected in the provisions of general and special legislation. Considering the main directions of the development of Russian law in the regulation of digital platforms, the following can be distinguished.

\subsection{Restriction of the Merger of Digital Platforms}

Such a restriction should be applied by the Federal Antimonopoly Service of Russia to all mergers within the framework of the federal law "On Protection of Competition" [2]. The merger of organizations allows removing a potential competitor and gain access to the data of consumers (customers) and their confidential information as a result of the acquisition. Thus, it is advisable to envisage obtaining preliminary permission for large digital platforms (for example, Google and Facebook) for the acquisition of any organization operating in the territory of the Russian Federation. Moreover, the place of registration of the organization, the Russian Federation or a foreign state, does not matter. Any association involves strengthening the financial situation and/or increasing the share of goods (services) in the digital market.

\subsection{Digital Advertising Supervision on Digital Platforms}

Within this area, several challenges facing the legislator can be identified. First, it is required to establish control over discriminatory behavior in vertically integrated digital platforms, if one prefers its business interests above the interests of advertisers or potentially competing companies. Second, when distributing advertising on common information platforms, it is required to provide for the possibility of a unified approach to establish requirements for the information provided by advertisers. And in the case of advertising intended for the Russian Federation, the relevant national legislation on advertising should be taken into account. Thirdly, it is required to fix the mechanism of taxation on advertising revenue on digital platforms if advertising is carried out outside the Russian Federation but advertisements are aimed at the Russian consumer.

\subsection{Copyright Protection}

Here the point is primarily in the content of digital platforms. We believe the positive effect will be the establishment of mandatory standards regarding the content on digital platforms that violate copyright. Therefore, it is advisable to provide for the enforcement of copyright on digital platforms by compulsory removal of materials that violate copyrights and the use of other mechanisms for their protection, provided for by the applicable Russian legislation.

\subsection{Reliability Control of News and Other Information Posted on Digital Platforms}

In this area, there are two options for the mechanism of establishing control. The first is self-regulation, which implies the voluntary initiative of digital platforms to ensure the reliability, fidelity, and availability of the source of news content presented to users. For example, companies may implement a code of digital platforms in their practice to counter misinformation, ensuring the reliability of news and other content but also address complaints of misinformation (inaccurate information created and disseminated with the intent to cause harm). The second is government regulation, which includes restricting the access of information companies to digital platforms (obtaining a license or other special permit, a restrictive ban on activities in connection with bringing the organization to administrative responsibility or in violation of the rights of a specific person (an undefined group of persons), based on a court decision in force, etc.).

\subsection{Protection of Confidential Information}

Due to the continuous development of digital technologies, the existing Russian legislation on the protection of personal data and other commercial information received by digital platforms is no longer enough to ensure its confidentiality. Here we see two ways of developing legislation. First, it is required to review the content of "personal information" and include technical data such as IP addresses, device identifiers, location data, and other online identifiers that can be used to identify the person. Second, one of the measures may be the mandatory addressing notification to the consumer. Notifications should be concise, transparent, written in a comprehensible language, and provided free of charge, which will help the consumer make an informed choice and control the way to collect, use, and disclose personal information. The consent to the processing of personal data, in this case, can be given by an individual for the entire period of the provision of services by the digital platform, and, in the case of an increase in the consumption of their products and services, the consent can be granted for any increase in the volume of personal information. 


\section{RESEARCH RESULTS}

\subsection{Theory of Data Control and Management}

The scientific literature repeatedly indicates that the consumer does not own its data provided by digital platforms [3]. In turn, digital platforms may use the data of the consumer of their services in different ways:

- to adapt services for a specific user;

- to study patterns of behavior of a common group of people based on a set of data obtained by the creation of "patterns" of behavior;

- to sell a specific product or service; and

- to sell information to entrepreneurs and/or to use it on its own later in another commercial way.

The main value for a digital platform is data on a specific consumer. Certain programs process information about purchases or trips of one customer and then predict the behavior of common people by providing advertisements for similar goods and services or by transferring an appropriate customer base to sellers of such goods or services. Even if the consumer did not make transactions on a digital platform but only used search queries, digital platforms read such information and use behavioral prejudices to their advantage. For example, the interest of citizens in tourism products increases in the summer. Let us suppose that a person requests the search engine not for specific travel agencies but for travel routes in a specific territory. Immediately an advertisement for travel agencies arrives on the account and offers similar routes and related content that may catch the consumer, limit its self-control (for example, using the information about the benefits of the climate of the territory, hospitals, or products manufactured there), and provoke it to a transaction.

By placing personal information on a digital platform, the consumer believes that it is able to manage it and, if desired, completely delete it. Do personal data really disappear without a trace after deleting? Let us suppose the client has deleted its data. If they were used by the company solely for its personalization, then there will be no traces of the presence of the customer in the data set and history. However, if the company has already used customer data to create a "pattern" of behavior, then deleting the data by the customer does not delete its presence on this platform, and its data will be used by the company in the future. The disadvantage of digital platforms is the lack of transparency in the collection and use of consumer data. Typically, a person connects to a platform or device, accepting the terms of the user agreement by pressing the button or the symbol "agree," "accept," or the like, often without having read the very terms. Understanding this, service providers are constantly striving to change the content of the agreement. The consumer is forced to re-accept the user agreement but with amendments, otherwise, it will be blocked. Such changes to user agreements are aimed at increasing the amount of information provided by the consumer and/or expanding its use for commercial and other similar purposes. The consumer does not even guess for what purposes this or that requested information is collected. For example, a person wants to purchase furniture. Upon registration, information on age and gender is requested. The question arises: for what purpose is such information collected? How can it affect the conclusion of the contract of sale and purchase of a particular product? The credentials collected, such as age, location, email address, etc., subsequently allow digital platforms to tag users and generate their data to other companies for a fee. And the more data about a user is collected by a digital platform, the more extensive opportunities it acquires to use them.

\subsection{Theory of Gratuitousness of the Services of Digital Platforms}

Most of the services provided by the digital platform are free. That is, the cost of services whose competitive price, for example, is 100 rubles, is sold at a cost of 0 rubles. This is the price, at which the digital platform acquires personal information from the consumer. The question is why digital platforms are profitable when providing free services to users [4]. The desire of the consumer to receive the service free of charge (whereas in the real market, this service would cost significant funds) allows digital platforms to expand their participation to the maximum possible audience. The purpose of this expansion is to generate revenue from advertising or to provide personal data to Internet companies for the purpose of network distribution of goods (services).

The implications of providing digital platform services for free is not hard to imagine. First, by increasing the circle of consumers of services, digital platforms bear more and more expenses that require compensation. Of course, the larger the number of consumers, the higher the advertising revenue. However, the desire for excess profits encourages digital platforms to minimize costs by reducing the quality of services provided (for example, reducing the level of privacy protection). Therefore, the assessment of the cost of services of a digital platform should not be analyzed in digital terms, only based on the condition of its quality.

Secondly, the elimination of competition and the impact on the market structure is carried out by digital platforms when establishing a zero price for the service. In the conventional product market, the customer base is formed at levels, depending on the price and quality of the goods. Some consumers prefer a lower quality product at a lower price, while others, on the contrary. An entrepreneur who wants to cover as wide a client base as possible will strive to provide different consumers with different quality products of the same category. In an attempt to retain consumers, the seller (service provider) will try to introduce new technologies and innovations aimed at improving the quality of its products, which invariably entails an increase in its costs. However, it is a required condition for further maintaining its presence in the product market. 
On the online market, improving the quality and introducing innovations in the final product (service), both provided by entrepreneurs and digital platforms, is not a prerequisite for maintaining their customers and income. The free entry of entrepreneurs into the digital market is motivated by the opportunity to earn extra profits. Digital platforms stimulate the entry of any participant into the market, knowing in advance that by providing each of them with relevant information about a specific level of consumers, they will receive a guaranteed income. Whereupon, the quality of the product (service) or content may not matter. Let us try to simulate one of the possible behaviors on the example of summer vacation. A person thinking of the possibility of a summer vacation receives relevant advertising and/or content. The digital platform uses behavioral weaknesses and consumer prejudices for profit, for example, hyperbolic discounting and limited self-control. Let us suppose that a digital platform provides advantages to some advertising or content providers over others by conspiring with them in order to maximize revenues, and as a result, to eliminate competition. Being on a specific digital platform, the consumer has no choice, considering that the technical selection of information is absolutely aimed at satisfying its interest as beneficially as possible. Consumers should assume that the increase in the cost of advertising and other services provided by the digital platform to entrepreneurs is subsequently paid by them in the form of mark-ups on goods and services sold. Digital platforms may also change the market structure by increasing or decreasing the number of a certain type of entrepreneurs and/or the goods or services they provide. For example, since the beginning of 2020, consumers have developed an increased demand for disinfectant products during the COVID-19 coronavirus pandemic. It is produced, first of all, by the posted content about the disease and its consequences, which results not only in an increase in sales for such goods but also in excess profit from overpricing at the peak of consumer demand. In a similar way, a digital platform may artificially generate demand for any product and, thus, allowing or eliminating entrepreneurs from the online market. Digital platforms are able to use such actions to manage the market structure and eliminate competition completely.

\subsection{Theory of Digital Platform Competition}

The market power of large digital platforms is quite stable. Digital platforms are developing econometric and simulation tools to measure behavior and influence on market factors that are not recognized as violations. Considering the theory of "gratuitousness" of services of digital platforms, we came to the conclusion that they can fully control competition in the market. For example, the provision of "free" goods and services. To develop these conclusions further, we may realize that setting the price of goods (services) at the level of 0 rubles not only crowds out competitors who set their real prices but also allows digital platforms to remain outside the scope of antitrust laws. Thus the Russian legislation, for example, provides for responsibility for violation of the pricing procedure if the price is regulated by the state [5]. But, when the price of a product (service) is 0 rubles, it is impossible to apply a measure of responsibility. The established concept of the cost of goods or services [6], below which the entrepreneur is not entitled to sell them, is often not applicable to digital platforms as well, due to the fact that the costs of digital goods (services) are close to zero. Even if the antimonopoly authority or private person tries to hold a digital platform accountable for violating the law, the possibility of making a decision in favor of the plaintiff is unlikely. The uncertain position that digital markets occupy is based, first of all, on the classical theoreticallyoriented approach of proving violations of antitrust laws. Some facts are difficult to confirm with direct evidence. Only indirect evidence may exist, which will not help the court to deliver a decision on the recognition of a violation. The likelihood of such systematic actions being committed by digital platforms is quite high.

The violation of antitrust laws always involves harm to competition. Damage caused by the offense can be compensated by penalties and orders to eliminate it. However, attracting the digital platform and/or perpetrators to administrative or criminal responsibility does not allow restoring competition in the digital market. Let us suppose that the legal obstacle to access to the digital market by a minor competitor to a digital platform has been eliminated. After bringing the latter to justice, its dominant position, which existed even before the violation, is maintained. Of course, one court decision to remove the obstacles to a competitor's access to the digital market will contribute to the elimination of all similar violations (but is not mandatory since case law does not apply in Russia). At the same time, each specific similar case requires collecting a set of evidence that clearly does not meet the principles of healthy competition.

\section{AUSTRALIAN APPROACH}

Given the increased privacy risks in the digital platform sector, which challenge the ability of consumers to make informed decisions about their personal information. It is not surprising that many states are taking steps to introduce more stringent regulatory data protection measures.

Australia currently has a unique privacy code that may apply to certain industries or occupations, in accordance with Part IIIB of the 1988 Privacy Act [7]. For example, the 2014 Code of Confidentiality (Credit Reporting) [8] specifically addresses the issues and risks of credit reporting confidentiality.

Australia is continuing to reform privacy laws and is considering the development and implementation of the Digital Platforms Privacy Code, which is scheduled to launch in 2020.

In the case of the implementation of the Digital Platforms Privacy Code, requirements will be put with respect to the consent mechanism for the collection, use, and disclosure of personal information, the processing of children's data, information security and data storage, and complaints 


\section{ACKNOWLEDGMENT}

ing procedures. Two privacy principles will apply here: notification and consent. Actually, the Digital Platforms Privacy Code prescribes digital platforms to take all measures to process data, threatening to hold them accountable in accordance with the Privacy Act [9].

In addition to the Digital Platforms Privacy Code, the possibility of wider reforms of the very Privacy Actis being considered, particularly, the establishment of more stringent requirements for consent to the processing of consumer data; broader definition of personal information, including technical data and location data; measures requiring the removal of personal information upon request; direct right to actions of persons in the case of serious intrusions in their personal lives [10]. A robust privacy structure maintains public confidence in the use of their personal data to stimulate innovation and economic growth [11].

\section{CONCLUSIONS}

The rules of common law that are currently in force may no longer solve the problems facing society and the state. The technological breakthrough over the past ten years has changed the structure of the market and requires new approaches to its regulation. New legislation should not allow double standards for entrepreneurs operating in the traditional and digital markets. However, the application of unified mechanisms for regulating relations in these two markets is not possible. Future legislation should be economically oriented and reflect the realities that have actually developed. Legal uncertainties allowing digital platforms to remain unaffected by them should be eliminated.

The presented three theories of the activity of digital platforms can serve as the base not only for antitrust law but also for the antitrust doctrine in general. The development of a new system for establishing facts of violation of antitrust laws is required in order to bring digital platforms to justice. Most likely, this system will differ from the general understanding of the theory of evidence. Digital platforms may create competitive threats to other participants in the commodity and digital markets, therefore, it is required to eliminate the uncertain position of them in the Russian market. It is advisable to develop a methodology for restoring violated competition by a digital platform and create a set of special legal remedies against violations of antitrust laws that ensure the longterm protection of rights.

The creation of new models and mechanisms for the legal regulation of the activities of digital platforms in Russia is generally aimed at socio-economic protection, which will ensure consumer rights, transparency of entrepreneurs, support for competition, and the security of confidential information.
The work is performed according to the Russian Government Program of Competitive Growth of Kazan Federal University.

\section{REFERENCES}

[1] H. Feld, The Case for the Digital Platform Act: Market Structure and Regulation of Digital Platforms, 2019, 216 p. URL: https://rooseveltinstitute.org/wpcontent/uploads/2019/05/Case-for-the-Digital-PlatformAct-final.pdf

[2] O zashchite konkurencii: feder.zakon ot 26.07.2006 № 135-FZ // Sobranie zakonodatel'stva RF, 2006, № 31 (ch.1), St. 3434.

[3] B. Cammaerts, R. Mansell, ORCID: 0000-00033950-3468 (2020) Digital Platform Policy and Regulation: Toward a Radical Democratic Turn, International Journal of Communication vol. 14, 2020, pp.135-154, ISSN 1932-8036. URL: http://eprints.lse.ac.uk/102628/6/untitled.pdf

[4] N. Economides, I. Lianos, Restrictions on Privacy and Exploitation in the Digital Economy: A Competition Law Perspective, Centre for Law, Economics and Society (CLES), Faculty of Laws, UCL London, WC1H 0EG, Research Paper Series, vol. 5, 2019, pp. 4-76. URL: https://www.ucl.ac.uk/cles/sites/cles/files/cles-52019.pdf

[5] Kodeks Rossijskoj Federacii ob administrativnyh pravonarusheniyah: feder.zakon ot 30.12.2001 № 195FZ // Sobranie zakonodatel'stva RF, 2002, № 1 (ch.1), St. 1.

[6] Nalogovyj kodeks Rossijskoj Federacii (chast' pervaya): feder.zakon ot 31.07.1998 № 146-FZ // Sobranie zakonodatel'stva RF, 1998, № 31, St. 3824.

[7] Privacy Act, 1988, No. 119, (Includes amendments up to: Act, 2013, No. 13), Federal Register of Legislation - Australian Government. URL: https://www.legislation.gov.au/Details/C2014C00076

[8] Privacy (Credit Reporting) Code 2014 (Version 2), 24.04.2014, No. F2018L00925, Federal Register of Legislation - Australian Government. URL: https://www.legislation.gov.au/Details/F2018L00925

[9] Digital Platforms Inquiry. Australian Competition and Consumer Commission, 2019, 623 p. ISBN 9781920702052 . 
https://www.accc.gov.au/system/files/Digital\%20platfor ms\%20inquiry\%20-\%20final\%20report.pdf

[10] K.Sainty, Australia: A Privacy Code for the Digital Platforms Sector, Feb. 2020. URL: https://platform.dataguidance.com/opinion/australiaprivacy-code-digital-platforms-sector

[11] OAIC welcomes privacy law update to protect Australians' personal information, 26 July 2019, Australian Information Commissioner and Privacy Commissioner. https://www.oaic.gov.au/updates/news-and-media/oaicwelcomes-privacy-law-update 